IZA DP No. 8572

Language and Labor Market Success

Ingo E. Isphording

October 2014

Forschungsinstitut zur Zukunft der Arbeit Institute for the Study of Labor 


\title{
Language and Labor Market Success
}

\author{
Ingo E. Isphording \\ IZA
}

\section{Discussion Paper No. 8572 \\ October 2014}

\author{
IZA \\ P.O. Box 7240 \\ 53072 Bonn \\ Germany \\ Phone: +49-228-3894-0 \\ Fax: +49-228-3894-180 \\ E-mail: iza@iza.org
}

\begin{abstract}
Any opinions expressed here are those of the author(s) and not those of IZA. Research published in this series may include views on policy, but the institute itself takes no institutional policy positions. The IZA research network is committed to the IZA Guiding Principles of Research Integrity.

The Institute for the Study of Labor (IZA) in Bonn is a local and virtual international research center and a place of communication between science, politics and business. IZA is an independent nonprofit organization supported by Deutsche Post Foundation. The center is associated with the University of Bonn and offers a stimulating research environment through its international network, workshops and conferences, data service, project support, research visits and doctoral program. IZA engages in (i) original and internationally competitive research in all fields of labor economics, (ii) development of policy concepts, and (iii) dissemination of research results and concepts to the interested public.
\end{abstract}

IZA Discussion Papers often represent preliminary work and are circulated to encourage discussion. Citation of such a paper should account for its provisional character. A revised version may be available directly from the author. 


\section{ABSTRACT}

\section{Language and Labor Market Success}

This article summarizes three different strands of the literature that address the labor market effects of language-related human capital. (1) A general importance is demonstrated in the empirical evidence on earnings and employment effects of literacy as the ability to productively use written information. Significant effects are found for developed and developing countries, leading on an aggregated macro level to a positive relationship between literacy and economic development. (2) The ongoing globalization leads to an increased demand for foreign language proficiency to reduce search and information costs and overcome cultural barriers in the trade of services and goods and tourism. Against the background of scarce skill supply, employers are willing to pay significant wage premia, especially for global and local lingua franca. (3) For international migrants, destination language skills display both a prerequisite for and outcome of successful integration. Investments into destination language skills are highly rewarded by wage returns and higher employment probabilities and act as the medium of translation to apply pre-migration human capital in the destination country labor market.

JEL Classification: J24, J31, J61

Keywords: language, literacy, human capital, returns, productivity, wage formation, foreign languages, immigration, integration, assimilation, linguistic barriers, linguistic distance

Corresponding author:

Ingo E. Isphording

IZA

P.O. Box 7240

53072 Bonn

Germany

E-mail: isphording@iza.org

\footnotetext{
* This manuscript was prepared for the International Encyclopedia of Social and Behavioral Sciences, 2nd Edition. All remaining errors are my own.
} 


\section{Introduction}

Proficiency in a language is one of the most basic parts of an individual's human capital portfolio. The productive functions of language are manifold, in both the labor market and everyday life. Language is used to express one's emotional status, providing the counterpart with necessary information on the otherwise unobservable inner state of mind, as well as expressing one's own identity and demands. Language is used as the main medium of social interaction. While this interaction does not necessarily contain any information conveyed, it provides the basic conditions for a productive environment. Language is the medium used for the record-keeping, organization and processing of information and facts. Finally, the concept of linguistic determinism in linguistics states that language determines the way in which individuals are able to think and structure their own thoughts (Crystal, 2010).

The importance of language skills in the labor market has been growing during recent decades, in a process that is likely to continue for some time. The reduced demand for manual labor and the ongoing transformation of the labor market towards increasingly information-based production has drastically increased the need for language and literacy skills. Especially with the emergence and diffusion of ICT usage into any niche of the labor market, there are hardly any occupations do not require a minimum of speaking, writing and reading skills.

Possessing a sufficient level of literacy and language proficiency is far from being self-evident. Literacy rates across countries differ substantially, with an even greater heterogeneity within countries. Literacy and language proficiency are crucially related to socio-economic status, education, health and nativity. This interrelationship between an individual's socioeconomic environment and the language-related human capital introduces a large heterogeneity in language skills. Given the productive value of language skills, this heterogeneity is likely to be translated into labor market disadvantages for individuals possessing insufficient levels of literacy and language proficiency.

This article aims to provide an overview of the empirical evidence on how literacy and language skills depend on socioeconomic characteristics and affect individual labor market outcomes. The empirical evidence is summarized via three different angles that have gained attention in the literature: Section 2 deals the importance of language in general, as the main medium of communication, recording and storing of information and the expression of demands; Section 3 summarizes the literature on the importance of foreign languages in modern interdependent economies; and Section 4 provides an overview on the literature on the importance of the destination language acquisition of immigrants for the economic and societal integration. Finally, Section 5 concludes.

\section{Literacy and productivity}

As the main medium of everyday communication, language plays a naturally important role in shaping the economic success of an individual, although the analysis of determinants and labor market advantages of skills in one's own mother tongue lack a natural theoretical framework and is ultimately data-driven. Language skills in one's mother tongue affect the productivity in the work place in the form of literacy. UNESCO defines literacy as: 
'the ability to identify, understand, interpret, create, communicate and compute, using printed and written materials associated with varying contexts. Literacy involves a continuum of learning in enabling individuals to achieve his or her goals, develop his or her knowledge and potential and participate fully in community and wider society' (UNESCO 2004)

Literacy therefore represents the productive functions of one's language ability. In recent years, the data availability on the relationship between adult literacy and labor market outcomes has improved substantially. In particular, the OECD has pushed forward data collection on literacy skills, with three subsequent international surveys now collecting literacy scores based on test booklets, as well as comprehensive information on socio-economic living conditions: the International Adult Literacy Survey (IALS) conducted in 1994-1998, the Adult Literacy and Lifeskills (ALL) Survey conducted in 2003-2008 and the Program for the International Assessment of Adult Competencies (PIAAC) conducted in 2012. These datasets provide the basis for a range of studies analyzing the determinants and labor market effects of adult literacy.

The evidence suggests that basic literacy skills are associated with distinctive wage premia. McIntosh and Vignoles (2001) provide estimates for positive wage and employment effects for UK, noting that around 20 percent of the British population had severe literacy difficulties in 1999. These literacy difficulties are associated with a sizeable wage penalty of about 15 percent. Using Canadian data, Charette and Meng (1998) show that literacy has a significant positive effect on wages, with their findings indicating that literacy is closely associated to formal education. Nonetheless, the wage effect goes beyond the returns of formal education, with literacy skills providing additional information in explaining wage differentials.

The relationship between literacy and economic well-being holds specific importance for developing and newly industrialized countries, given that literacy is crucially dependent on a well-developed and functioning education system. Therefore, developing countries might display significantly lower literacy rates than developed countries, although appropriate data are scarce in these countries. De Baldini Rocha et al. (2011) analyze the effect of literacy on earnings in Brazil, finding both significant employment and earnings effects of becoming literate. This evidence on the micro level is complementary to macro evidence on the relationship between literacy rates and the economic development of regions and countries. Aggregated literacy rates provide insights into the human capital stock of a country. Coulombe and Tremblay (2006) use data from the IALS study to explain the growth of 14 OECD countries by the literacy of labor market entrants. They show that literacy has a significant positive effect on growth indicators and conclude that raising the average level of literacy (e.g. by investing into women's education) is more important than focusing on high levels for restricted groups. Hanushek and Woessmann (2008) provide an overview of the relationship between cognitive skills (including literacy), individual labor market outcomes and economic growth, highlighting the importance of educational policy measures for countries' development. Following this importance for the economic development of countries, literacy has entered the UN Human Development Index as a main dimension of measurement.

\section{Foreign languages in the labor market}

In an increasingly interconnected globalized world, international communication plays a growing and crucial role as a prerequisite for international factor movements, international 
trade, foreign direct investments, financial flows and human migration. This leads to a worldwide growing demand for foreign language proficiency that is not always met by skill supply.

The acquisition of reading and speaking skills in a foreign language can be modeled as the economic decision weighing off the expected benefits and costs of speaking a new language. Formalized models are provided by Selten and Pool (1991) and Church and King (1993). The expected benefits of speaking a new language combine utility gains through being able to communicate in a certain language. The benefits and incentives of learning a new language can be divided into internal and external motivations. Internal motivations mainly refer to the nonmarket value of languages. Speaking a new language offers potential utility gains through easier access to new information and an increased population of potential communication partners. Furthermore, it also offers increased reputation, prestige and recognition among peers. For some, the learning process itself might lead to utility gains through being a joyful process.

From an economic perspective, this non-market value of languages is accompanied by a market value related to the relative importance of a language to a country. This relative value is dependent on a range of factors: it is shaped by the applicability of a language in direct communication with foreign customers in tourism and services. Its value is related to its potential in international trade to reduce search, translating and information costs when dealing with foreign information. In particular, the latter role of languages in shaping international trade flows has gained significant attention in the economic literature. Although English acts as lingua franca in modern international trade, knowledge in the trade partner's original language remains a crucial variable, especially in the development of long-term business partnerships and overcoming further cultural hurdles. Further, lower linguistic barriers ease the promotion of trade and commerce by immigrants through easier access to the destination country, as discussed later in Section 3. A range of studies proxies these linguistic barriers by summary statistics of linguistic distance between two trade partners, using grammatical information (Lohmann 2011) or information on pronunciation of word lists (Isphording and Otten 2013). Common findings of these studies are significantly reduced trade flows by higher linguistic hurdles.

On the micro level, language barriers are translated into expected benefits of learning a new language by the willingness of employers to pay for foreign language proficiency. Individuals have to weigh these potential utility gains from learning a new language against the costs associated to the language acquisition. These costs come in terms of direct monetary costs for language classes and indirectly by spent effort and foregone wages. The size of the costs is related to a range of correlates. Apart from a fundamental and unobservable heterogeneity in the ability to learn languages, the difficulty of learning a new language is influenced by the dissimilarity between the first language and the acquired language. Dissimilarities between languages raise large barriers in the acquisition process. While it might be comparably easy to learn a language from one's own language family (e.g. German, English and Swedish from the Germanic language family, or Romanian, Spanish and Italian sharing the Romance language family), the acquisition becomes much more difficult for linguistically distant languages, e.g. for a European attempting to learn Mandarin or Japanese. Isphording and Otten (2013) provide an extensive analysis of the role of linguistic borders in language acquisition. Another crucial determinant of the costs of language acquisition is the age at which the language acquisition takes place. Linguistic and neurobiological research has identified a crucial "critical period" in early adolescence until when language acquisition takes place almost effortlessly. The ability to 
acquire new languages subsequently decreases, in a process that continues into adulthood. As second language education is typically associated with secondary schooling, most of the foreign language acquisition takes place after this critical period. Acquiring a new language in adulthood faces an even more reduced ability to learn.

A rational and utility maximizing individual will weigh these costs of language acquisition against expected benefits of speaking the new language. Ginsburgh and Prieto-Rodriguez (2011) provide an overview on returns to foreign languages in the EU. Their results indicate distinctive wage premia paid for foreign languages, with a strong heterogeneity across different countries and the wage distribution. Knowledge of foreign languages mainly pays off in high-skilled occupations. While English as the main lingua franca is rewarded in any country, in Southern European countries it competes in importance with Romance languages, which seem to play the role of local lingua franca, such as French in Spain. This importance is backed up by Isphording (2013), who estimates large returns to foreign language skills within a sample of immigrants in Spain. Again, the highest returns are paid for English skills, closely followed by the returns to French skills.

Furthermore, Williams (2011) finds significant positive returns to foreign language skills in Western European countries, which he relates to the importance of incoming tourism from specific language groups. Here, a similar logic as in the case of international trade applies, whereby tourism flows increase the applicability of language skills in the service sector, as well as employers' willingness to pay for proficiency in a specific language.

\section{Destination language skills of migrants}

The best-researched field regarding the labor market effects of languages is the importance of destination language skills of international migrants. Language skills are the most important and visible part of the human capital an immigrant acquires during his or her migration history. The consideration to invest into proficiency in the destination country language heavily influences the economic success in the host country. However, even prior the migration decision, the expected costs of later language acquisition, e.g. in the form of perceived linguistic borders, shape the initial decision to migrate itself, thereby influencing aggregated migration flows along linguistic borders (Adsera/Pytlikova 2012).

As the decision to invest in the destination language is a conscious one (contrary to the acquisition of a first language, but similar to the acquisition of foreign languages discussed in the former section), it is appropriately analyzed in a human capital framework, weighing off expected benefits and costs of the language acquisition. Chiswick and Miller (1995) distinguish the determinants of language fluency of immigrants into three categories related to the exposure to the destination language, the efficiency in learning a new language and the economic incentives derived from being able to communicate in the destination language. Exposure and learning efficiency, dependent on individual, institutional and situational characteristics, shape the costs in terms of effort or monetary costs for language classes, while economic incentives display the expected benefits formed by increased opportunities for economic integration and social participation. 
The exposure to the destination language can be divided into prior and post migration exposure. Prior to migration, emigrants might learn about the destination language by being educated in secondary school and reading non-translated literature and watching dubbed movies. Post migration, exposure to the destination language will mainly be a non-directed process dependent on the time of residence in the country. The exposure is also dependent on an individual's socioeconomic situation, with the labor market status, working full-time, being unemployed or out of the labor force, influencing the degree of exposure. The decrease in exposure when individuals are not or unemployed is especially pronounced when living in a socioeconomic enclave. Such a linguistic enclave further reduces incentives to acquire proficiency in the destination country by restricting the range of opportunities where this language can be applied.

Immigrants differ in their ability or efficiency in acquiring the destination language. This ability is shaped by cognitive ability, education that might be influenced by selection processes in migration. A major factor influencing the ability to learn new languages is the age at arrival, given that this determines the ability to acquire the new language according to the linguistically based critical period hypothesis discussed earlier. Immigrants arriving in young ages before this critical period in early adolescence pick up the destination language almost effortlessly and reach a near native level of proficiency. For immigrants arriving after the critical period, the ability to learn new languages is distinctively decreasing.

A second linguistically based factor influencing the ability to acquire proficiency in the destination language is the linguistic distance between the mother tongue and the language to acquire. The linguistic origin turns proves a major determinant of destination language proficiency, outweighing further socioeconomic correlates and determinants. The effect of linguistic distance interacts with the effect of age at arrival: while young immigrants are unlikely to be affected by their linguistic origin, the additional costs in the language acquisition associated to a distant linguistic origin are substantial for later arrivers who start acquiring the new language after the critical period (Isphording and Otten 2013).

The third group of influencing factors (besides exposure and efficiency) constitutes the economic incentives of language proficiency in the destination language. The willingness to invest into the language proficiency mirrors the expected benefits. While parts of these benefits and utility gains will be due an increased potential in social and cultural participation, economists tend to focus especially on labor market advantages.

The estimation of labor market effects of language skills is confounded by a number of empirical pitfalls, measurement error, unobserved variable bias and simultaneity. First, with objective assessments of language skills being a rare exception, studies addressing the destination language proficiency of migrants are typically restricted to self-reported information on language skills. This subjective information is likely to be prone to a severe measurement and misclassification error. Second, analogously to the estimation on returns to education, estimates for effects of language proficiency are likely to be biased by omitting unobservable ability from the regressions. Both wages and language skills are potentially positively affected by an unobservable (to the researcher) ability.

Recent studies have attempted to address these empirical issues by instrumental variable regressions. This technique relies on the assumption that there exists an observable variable that affects the language acquisition but is unrelated to the sources of the empirical pitfalls, 
namely the measurement error, the unobserved ability and the labor market outcomes itself. With this instrument variable, exogenous levels of language skills can be predicted, which are then used to estimate the actual effect of language proficiency.

Due to the omnipresence of language in everyday life, such an instrument variable is hard to find. Initially, Chiswick and Miller (1995) proposed using parental education, family composition and family ties abroad as valid instruments. Their estimates for the US, Canada and Israel indicate severely downward biased OLS estimates but distinctive wage premia estimated by IV between 30 and 50 percent for speaking English "Well" or "Very Well". Dustmann and Van Soest (2002) attempt to address the measurement error by using time-adjusted averages and lags and leads of self-reported measures of language proficiency from panel data of the German Socio-Economic Panel. Their sample is restricted to German "guest-workers", immigrant bluecollar workers from Mediterranean countries, enlisted to fulfill the excess labor demand after WW2. They conclude that estimates from uncorrected OLS regressions are severely downward biased. Their results indicate a wage premium for speaking German "Well" or "Very Well" by about 11-14 percent, which exceeds the OLS estimates by a factor of 2 to 3 .

Using data from the 1990 US Census, Bleakley and Chin (2004) focus on childhood immigrants in the US who arrived at an age younger than 17. Their identification relies on the so-called critical period of language acquisition, based on the empirical evidence of a decreasing ability to learn languages after reaching adolescence. Linguists and neurobiologists state that children are able to acquire a language effortlessly up to a native level until this critical period, while this ability decreases distinctively thereafter. Bleakley and Chin use this structural break to compare young and old arriving immigrants, while additionally controlling for whether the immigrants originates from an English- or non-English-speaking country. By using this double comparison groups, they again state that uncorrected OLS estimates are severely downward biased. In their estimates, an increase in language ability on a 0-3 scale ( $0=$ not at all, $3=$ Very well $)$ is associated with a wage premium of around 30 percent. Using more recent data from the American Community Survey 2010, Isphording and Sinning (2012) extend their analysis to the overall population of immigrants in the US, substituting the age at arrival with the exposure to English by time of residence. Their results confirm the initial results for child migrants for both child and adult migrants.

While these causal IV estimations provide a robust estimate of the importance of language skills for the economic integration of immigrants into a host country, they provide little insight into the channels through which the language skills affect labor market outcomes. Indeed, only a few studies have gone into detail in this regard. Bleakley and Chin (2004) identify schooling as a major channel through which language skills affect the earnings of child migrants. Child migrants from non-English-speaking countries arriving in early years possess on average 2 years of additional schooling compared to their late-arriving counterparts. The additional schooling is able to explain almost the complete causal effect of language on wages. Isphording and Sinning (2012) confirm the importance of education as a mediating channel for child migrants, although their results neglect this importance for immigrants arriving in adulthood (who acquired their education in the sending country).

Chiswick and Miller (2010) address the occupational choice of immigrants regarding the language requirements of occupations as a mediating channel of language skills on wages. They combine data from the 2000 US Census with scores for English requirements measures taken from the $0^{*}$ NET database. Their results indicate a strong effect of language probability on the job 
choice, whereby good job matches in terms of language skills and requirements are rewarded by wage premia. Berman et al. (2003) use Israeli survey data to assess a potential complementarity between immigrant language proficiency and further human capital. Their results indicate a strong heterogeneity in the effect of language proficiency on wage growth across occupations. As the language acquisition is only relevant for high-skilled professions, the authors interpret this as evidence for the complementarity between language proficiency and further human capital. Chiswick and Miller (2003) use 1991 Canadian Census data to show a similar complementarity between pre-migration schooling and experience and the destination language skills. Language skills act as the translating medium to apply pre-migration acquired human capital into the host country labor market.

Aside from these studies focusing on the earnings effects of wages, further studies have shown additional effects of language proficiency on labor-market related outcomes. Aldashev et al. (2009) document the impact of German language use on labor supply decisions and unemployment probability using German household data from the Socio-Economic Panel. They conclude that language proficiency significantly affects the probability of labor market participation and subsequent employment. Dustmann and Fabbri (2003) analyze the language skills of ethnic minorities using UK survey data. Besides significant earnings effects, they also find a higher employment probability of around 20 percent for individuals who are proficient in English.

Finally, besides heterogeneity in the level of proficiency, a second mechanism can arise through which language differences can affect labor market outcomes. Differences in language do not necessarily mean vertical differences in proficiency, but can also appear in the form of a horizontal differentiation through dialects or accents, speech patterns or choice of words. These differences can act as a signal providing information on social status and ethnicity and allow for taste-based or statistical discrimination. Grogger (2011) provides evidence of an influence of racial speech patterns in the US. Using unique data from the 1997 National Longitudinal Survey of Youth (NLSY) augmented with anonymously rated speech patterns, he identifies a significant wage penalty of around 12 percent for speaking African American English instead of Standard American English.

\section{Conclusion}

This article aimed at providing an overview of the economic literature addressing the relationship between language and productivity. Three different strands of literature have been summarized: (1) studies addressing the literacy of the native population and its effect on individual labor market outcomes and aggregated growth and development; (2) the labor market effects of foreign language proficiency against the background of a growing demand by globalization; and (3) the importance of destination language proficiency for the social and economic integration of immigrants.

All three strands of the literature provide comprehensive evidence for the crucial role played by language-related human capital in economic processes. As the key medium of communication, language crucially shapes economic outcomes on both the individual and aggregated level. 
The general importance of language-related human capital becomes apparent with empirical evidence on the labor market effects of adult literacy. For both developed and developing countries, studies demonstrate a positive effect of literacy on wages and employment probabilities that go beyond the effect of associated formal education. This micro evidence is accompanied by macro evidence linking the economic growth to literacy rates as a crucial driver of economic development.

The specific importance of language in the labor market has been fuelled by ongoing globalization. International trade in goods and services, tourism and migration flows increase the importance of foreign language skills. Foreign language skills are crucial in reducing search and information costs, as well as establishing long run business relations. This is especially true for English as the commonly accepted lingua franca in international trade. Proficiency in foreign languages is rewarded by employers though significant wage premia, especially in occupations related to services, trade and tourism.

Finally, the best-researched field against the background of language skills and the labor market is the importance of destination language skills for international migrants. The proficiency in the destination country is both a prerequisite for and an outcome of a successful integration into the host country. Immigrants weigh off costs and expected benefits to decide on their investment in terms of the effort and opportunity costs of language acquisition. Determinants of language skills, such as linguistic origin, age at migration, individual education and ability and enclave density shape a heterogeneous cost structure, while expected benefits are given by labor market advantages, in terms of higher wages and employment probabilities. Wage effects of language skills are heterogeneous across the occupational distribution, with requirements for language skills strongly differing between blue- and white-collar occupations. Language skills are shown to be complementary to further forms of pre-migration acquired human capital, acting as the medium of translation to apply home country knowledge in the host county labor market. 


\section{References}

Adsera, Alicia \& Mariola Pytlikova, 2012. "The role of language in shaping international migration,"

CReAM Discussion Paper Series 1206, Centre for Research and Analysis of Migration (CReAM), Department of Economics, University College London.

Aldashev, Alisher \& Gernandt, Johannes \& Thomsen, Stephan L., 2009. "Language usage, participation, employment and earnings: Evidence for foreigners in West Germany with multiple sources of selection," Labour Economics, Elsevier, vol. 16(3), pages 330-341, June.

Berman, Eli \& Lang, Kevin \& Siniver, Erez, 2003. "Language-skill complementarity: returns to immigrant language acquisition," Labour Economics, Elsevier, vol. 10(3), pages 265-290, June.

Bleakley, Hoyt \& Aimee Chin, 2004. "Language Skills and Earnings: Evidence from Childhood Immigrants," The Review of Economics and Statistics, MIT Press, vol. 86(2), pages 481-496, May.

Charette, Michael F. \& Ronald Meng, 1998. "Literacy and Numeracy," Canadian Journal of Economics, Canadian Economics Association, vol. 31(3), pages 495-517, August.

Chiswick, Barry R \& Miller, Paul W, 1995. "The Endogeneity between Language and Earnings: International Analyses," Journal of Labor Economics, University of Chicago Press, vol. 13(2), pages 246-88, April.

Chiswick, Barry R. \& Miller, Paul W., 2003. "The complementarity of language and other human capital: immigrant earnings in Canada," Economics of Education Review, Elsevier, vol. 22(5), pages $469-480$, October.

Chiswick, Barry \& Paul Miller, 2010. "Occupational language requirements and the value of English in the US labor market," Journal of Population Economics, Springer, vol. 23(1), pages 353372, January.

Church, Jeffrey \& Ian King, 1993. "Bilingualism and Network Externalities," Canadian Journal of Economics, Canadian Economics Association, vol. 26(2), pages 337-45, May.

Coulombe Serge \& Tremblay Jean-François, 2006. "Literacy and Growth," The B.E. Journal of Macroeconomics, De Gruyter, vol. 6(2), pages 1-34, August.

Crystal, D. (2010). The Cambridge Encyclopedia of Language. Third Edition. Cambridge University Press.

de Baldini Rocha, Maúna Soares \& Ponczek, Vladimir, 2011. "The effects of adult literacy on earnings and employment," Economics of Education Review, Elsevier, vol. 30(4), pages 755-764, August.

Dustmann, Christian \& Francesca Fabbri, 2003. "Language proficiency and labour market performance of immigrants in the UK," Economic Journal, Royal Economic Society, vol. 113(489), pages 695-717, 07.

Dustmann, Christian \& Arthur Van Soest, 2002. "Language and the earnings of immigrants," Industrial and Labor Relations Review, ILR Review, Cornell University, ILR School, vol. 55(3), pages 473-492, April. 
Ginsburgh, Victor A. \& Juan Prieto-Rodriguez, 2011. "Returns to Foreign Languages of Native Workers in the EU," Industrial and Labor Relations Review, ILR Review, Cornell University, ILR School, vol. 64(3), pages 599-618, April.

Grogger, Jeffrey, 2011. "Speech Patterns and Racial Wage Inequality," Journal of Human Resources, University of Wisconsin Press, vol. 46(1), pages 1-25.

Hanushek, Eric A. \& Ludger Woessmann, 2008. "The Role of Cognitive Skills in Economic Development," Journal of Economic Literature, American Economic Association, vol. 46(3), pages 607-68, September.

Ingo E. Isphording, 2013. "Returns to Foreign Language Skills of Immigrants in Spain," LABOUR, CEIS, vol. 27(4), pages 443-461, December.

Isphording, Ingo E. \& Sebastian Otten, 2013. "The Costs of Babylon-Linguistic Distance in Applied Economics," Review of International Economics, Wiley Blackwell, vol. 21(2), pages 354$369,05$.

Isphording, Ingo E. \& Sinning, Mathias, 2012. "The Returns to Language Skills in the US Labor Market," IZA Discussion Papers 7080, Institute for the Study of Labor (IZA).

Lohmann, Johannes, 2011. "Do language barriers affect trade?," Economics Letters, Elsevier, vol. $110(2)$, pages 159-162, February.

McIntosh, Steven \& Vignoles, Anna, 2001. "Measuring and Assessing the Impact of Basic Skills on Labour Market Outcomes," Oxford Economic Papers, Oxford University Press, vol. 53(3), pages 453-81, July.

Selten, Reinhard \& Jonathan Pool, 1991. The distribution of foreign language skills as a game equilibrium Game Equilibrium Models, vol. 4, Social and Political Interaction, Springer.

UNESCO, 2004. "The Plurality of Literacy and its implications for Policies and Programs". UNESCO Education Sector Position Paper: 13.

Williams, Donald R., 2011. "Multiple language usage and earnings in Western Europe," International Journal of Manpower, Emerald Group Publishing, vol. 32(4), pages 372-393, July. 